\title{
Injury and repair of tracheobronchial cartilage following accidental exposure to ethyleneimine
}

\author{
G. A. GRESHAM AND I. E. WEST \\ Department of Morbid Anatomy and Histopathology, Addenbrooke's Hospital and University of Cambridge
}

SYNOPSIS A fatal case following ethyleneimine inhalation is described. Profound destructive effects on tracheobronchial cartilage were found at necropsy after an interval of apparent recovery from the early phases of poisoning. The pathogenesis of these cartilaginous changes is discussed. It is proposed that they may have been due to proteases liberated from mucosal granulation tissue

Reports of accidental exposure to ethyleneimine $\left(\mathrm{C}_{2} \mathrm{H}_{5} \mathrm{~N}\right)$ in man are very few. This is a report of a single case which raises a number of fundamental problems about the factors concerned in the integrity of cartilage in the main air passages.

Ethyleneimine, also called axiridine, is volatile and highly reactive and is corrosive, attacking cork, rubber, many plastics, metals, and most glasses except those that are free of carbonate or borax.

The accident described here occurred when the chemical was being dispensed into small containers for use in a variety of processes including organic syntheses.

\section{Case Report}

A 57-year-old Caucasian man, who was employed as a storeman at a chemical firm, was exposed to ethyleneimine vapour in July 1973. The exposure time was probably not more than five minutes.

Quite soon afterwards he developed signs of irritation of the eyes, nose, and larynx; he salivated and vomited and became acutely breathless. He was promptly admitted to hospital where he was found to have pulmonary oedema. He required a tracheostomy and ventilation and was initially given large doses of hydrocortisone which were steadily reduced during the subsequent five weeks in the hospital. Shortly after admission his blood $\mathrm{pH}$ was $7 \cdot 58$, $\mathrm{PCO}_{2} 39 \mathrm{mmHg}, \mathrm{Po}_{2} 60 \mathrm{mmHg}$, and the standard bicarbonate level was $14 \mathrm{mEq} / \mathrm{l}$. Improvement occurred slowly over the next three weeks. At various times bacteria such as Pseudomonas, Staphylococcus, and Escherichia coli were grown

Received for publication 16 December 1974. from bronchial aspirates. He recovered from these infections and was gradually allowed off the respirator.

Five weeks after admission he was discharged from hospital and was really quite well apart from a moderate degree of breathlessness on exertion. The radiological appearances of the lungs were normal, he had ceased to produce sputum, and his blood gases, when breathing air, were $\mathrm{PCO}_{2} 30 \mathrm{mmHg}$ and $\mathrm{Po}_{2} 86 \mathrm{mmHg}$. The blood $\mathrm{pH}$ was 7.43 and the standard bicarbonate $19 \mathrm{mEq} / 1$.

Three weeks after discharge he rapidly became short of breath and developed a wheezy cough. He was found clinically to have extensive bronchospasm, and a loud tracheal stridor was also noted. He was readmitted to hospital and endoscopy showed extensive tracheal ulceration with conspicuous stenosis of the trachea, and the question of segmental resection of the trachea to relieve the condition was considered. This was not done partly because it was noted also that the trachea seemed unduly flaccid and tended to collapse on inspiration. He never really improved very much and two weeks after admission he died after becoming severely breathless.

NECR OPSY (P73-564)

He was still well nourished $(58 \mathrm{Kg} ; 1.8 \mathrm{~m}$ tall). Facies and other external appearances were not remarkable.

The principal findings were in the respiratory system. The tracheal mucosa was replaced by horizontal, purple strips separated by exposed, yellow islands of cartilage. Similar appearances were found in the main bronchi, the walls of which, like the trachea, were thickened. The main air passages 
were flabby and had collapsed to produce slit-like lumina. Both lungs showed conspicuous oedema and emphysema. A few white spots were observed in the mediastinal lymph nodes but, apart from a few small areas of subendocardial fibrosis, there was little abnormal elsewhere.

\section{Histopathology}

The most striking and unusual appearances were seen in the trachea and main bronchi. The mucosa of these tubes was largely replaced by granulation tissue which was occasionally polypoid. In a few areas the mucosa was fibrotic and replaced by layered collagen (fig 1). The amount of fibrous tissue in the mucosa was excessive when compared with sections of lower trachea from five subjects of comparable age who had died of cardiovascular disease.

In the areas of luxuriant granulation tissue replacement of the mucosa the cartilage of the tracheal wall was eroded (fig 2) and depleted of muco-

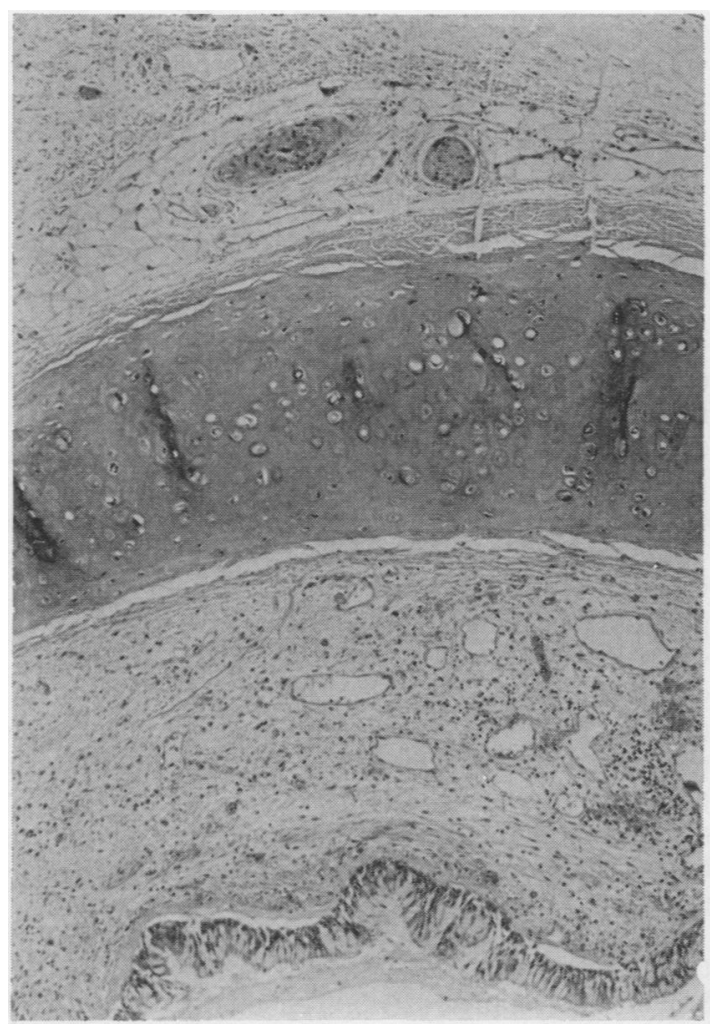

Fig 1 polysaccharide as determined by Hale's and Alcian blue methods, the latter being used at ranges of $\mathrm{pH}$. At these points also the cartilage was acutely kinked. Where fibrous tissue had replaced mucosal granulation tissue the adjacent cartilage appeared normal and contained stainable mucopolysaccharide near its surface.

Deeper in the lungs many of the smaller bronchi contained granulomatous polyps (fig 3) which, in some, entirely occluded the lumen. Patchy emphysema and bronchopneumonia were frequent findings in many sections of lung tissue. The white spots seen macroscopically in the mediastinal lymph nodes turned out to be sarcoid-like granulomas.

The findings taken together suggested that most of the symptoms were explicable by collapse of the weakened trachea and main bronchi on inspiration coupled with stenosis of small bronchi by granulomatous polyps.

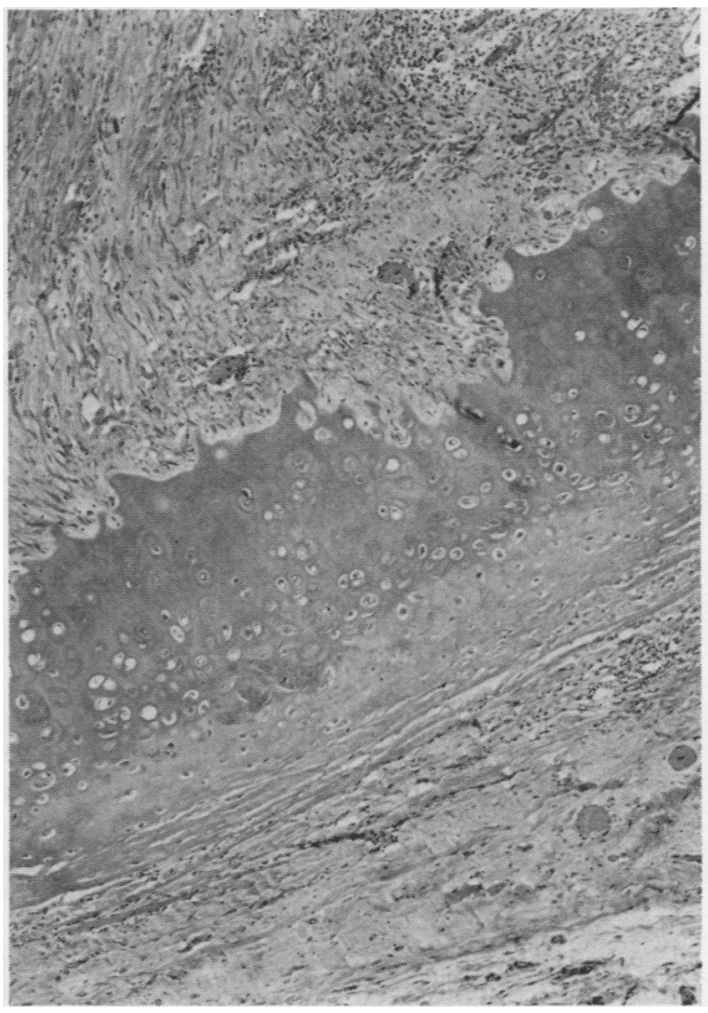

Fig 2

Fig 1 Vascular fibrous tissue replacing the bronchial submucosa. (Haematoxylin and eosin $\times 55$ )

Fig 2 Erosion of tracheal cartilage by vascular granulation tissue. (Haematoxylin and eosin $\times 55$ ) 


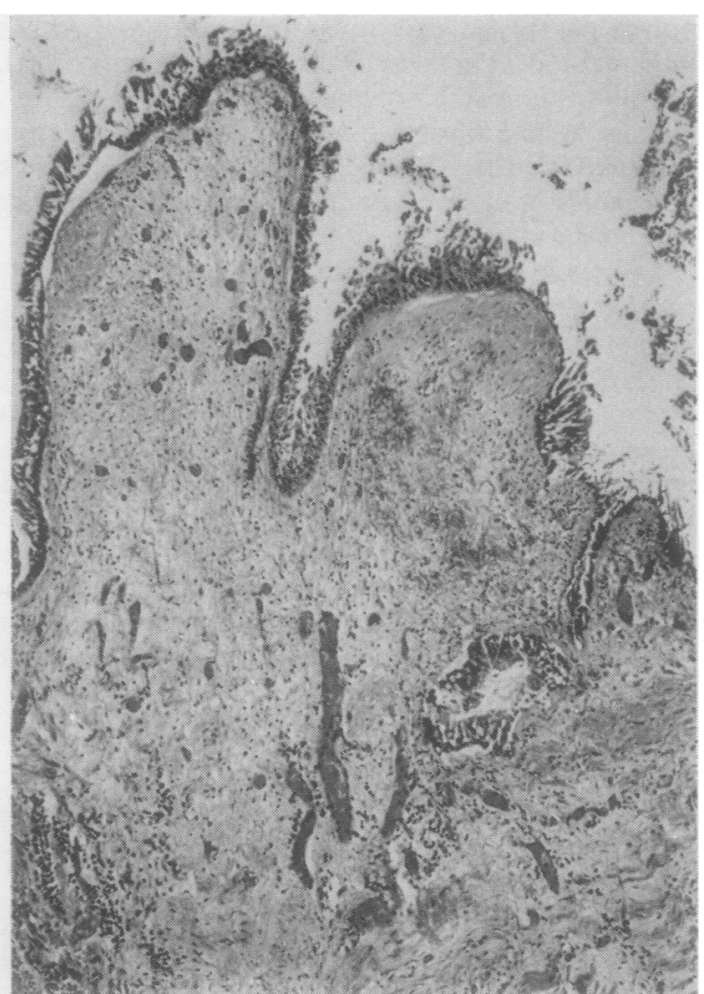

Fig 3 Granulomatous polyp arising from the mucosa of a second order bronchus. (Haematoxylin and eosin $\times 55)$

\section{Discussion}

The most remarkable feature of this case was that exposure to the irritant was followed by gradual recovery which was then succeeded by rapidly progressive respiratory obstruction due in part to failure of cartilaginous struts to support the tracheobronchial tree. The early phases of the illness are entirely explicable in terms of the direct irritant effect of the ethyleneimine; this caused extensive necrosis of the mucosa. It is likely that cartilaginous destruction was a later event in the sequence. The important question is why this damage to cartilage occurred at all.

Collapse of the trachea and bronchi is not a feature of most forms of tracheal ulceration but then the ulceration is not often as extensive as it was in this case. Most inhaled irritants cause bronchiolitis obliterans, as also occurred in this man, but these agents are not usually as potently exothermic injurious agents as is ethyleneimine. It might be that all could be explained by the extensively damaging effect of this substance but the gradual clinical improvement followed by rapid产 decline cannot be accounted for in these terms.

There is little help to be gained in the under- $\overrightarrow{\vec{D}}$ standing of the pathogenesis from previouslyo reported cases because they are so few and they areo not often accompanied by detailed histopathological $\bar{c}$. descriptions.

Most of the reported cases have been either of skin contamination with irritation and blistering ${ }_{-}^{\infty}$ or inhalation with irritation of the upper air pas-. sages (Thiess, 1965). In a few, both skin irritation $\vec{\omega}$ and pulmonary effects occurred. One subject whoo inhaled ethyleneimine for several hours died $\overline{0}$ within four days and the appearances of the tracheai were recorded as 'marked diphtheritic' in appearance.. The lungs showed pneumonia and oedema but allir this occurred after several hours' exposure to the ethyleneimine, unlike the case that is presently응 reported. The other recorded death occurred 19days after extensive skin contamination. Basically the appearances at necropsy were similar to those found in patients severely burned from other causes. $\vec{\varphi}$

The exposure involved in the case reported in this or paper was quite short. It has been suggested that ethyleneimine may also have a sensitizing effect, and this might explain the sequence of events in our patient, namely an initial irritant effect followed by delayed tracheal damage due to hyper- $-\frac{\mathrm{D}}{\mathrm{Q}}$ sensitivity. However, there is no firm agreement $\stackrel{\varrho}{\rightarrow}$ about the sensitizing effects of ethyleneimine (Thiess, 1965).

There is no clear indication in man of the size of the dose needed to produce dire effects. In our case the exposure was short and not intense. In five students reported by Weightman and Hoyle (1964) exposure lasted for two hours in a poorly ventilated room, but all recovered. All five patientso̊ complained of vomiting, eye irritation, and soreness of the throat which were not severe until almost threeo hours after the exposure. Within 12 hours they had $>$ profound hacking coughs but there were no clinicalo signs in the chest. In four patients a timed vital capacity test suggested mild obstructive pneu- $\odot$ monopathy. Two had ulceration of the upper $N$ respiratory tract. The main problem in all was persistent irritation of the eyes, and two hado residual conjunctival inflammation three months later. The same two patients had some slight im- $\frac{}{\Phi}$ pairment of timed vital capacity at that time.

In the rat and guinea pig concentrations higher 0 than $500 \mathrm{ppm}$ were rapidly lethal (Carpenter, 0 Smyth, and Shaffer, 1948). The changes most often $\stackrel{\odot}{\circ}$

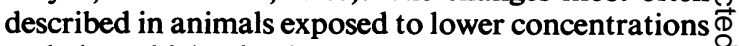
and in which death occurred some days after $\bar{O}$ exposure were mainly of renal tubular necrosis. In man, it is said that irritant effects do not occuro 
until $100 \mathrm{ppm}$ are present in the air and that 250 ppm are 'dangerous to life' if inhaled for an hour.

The case that we report is unique. Although it is quite clear that it is unlikely that the patient would have died had he not inhaled ethyleneimine, the important question is whether the damage to cartilage that subsequently caused the collapse of the air passage was the direct effect of the vapour.

The clues, we think, lie in the histological appearances: where the cartilage is eroded granulation tissue is in contact with it. Where fibrous replacement of the mucosa has occurred the cartilage cells and their matrix are intact. It is likely that the extensive cartilage erosion could have been caused by proteases liberated from granulation tissue, and the curiously biphasic nature of the illness in this case could be explained by the use of large doses of steroids in the early stages of treatment which has partly suppressed the initial inflammatory response. The subsequent slow development of granulation tissue might then be supposed to result in the progressive release of proteases. Cartilage is built rather like a rigid sponge, the meshwork consisting of collagen and the spaces being filled with highly hydrated molecules of proteoglycan (Barrett, 1971), mainly chondroitin sulphate $C$. When the protein skeleton is attacked by proteases the rigidity of the cartilage is lost. A similar phenomenon was observed by Thomas (1956) who injected the plant proteinase papain into rabbits and observed that the ears of the animal flopped like those of a spaniel. At the same time as collagen is lost proteoglycan also disappears from the cartilage.

Regeneration of cartilage cells and restoration of the proteoglycan constituents of the stroma is a slow process. Rao (1954) showed that as long as 75 days were needed before injury to cartilage healed by new fibrocartilage formation. Active mitosis after injury did not start for about 28 days. Restoration of proteoglycans was also a tardy affair, often taking as much as 12 weeks before it was completed (Sadiq, Sudhakar, Sathavivalya, Kangwalkai, and Enquist, 1973).

It is likely that the cartilage destruction in this case was due to the extensive delayed formation of granulation tissue rather than a direct result of ethyleneimine itself. Nevertheless this hypothesis needs to be tested by experiment on growing cartilage, and the results of these experiments will be reported later.

The changes in this case are reminiscent of those seen in chronic relapsing polychondritis (Harwood, 1958), but in this condition other cartilages such as those of the ears and nose were involved. Our patient showed no such stigmata.

One of the problems in unravelling the histopathology of this case was the difficulty of determining what was existing and what was regenerate cartilage. The presence of a dense fibrous lamina around the nuclei of regenerate cartilage cells is said to be an indication of a regenerated cartilage cell (Ghadially, Oryschak, and Mitchell, 1974). This can be detected by electron microscopy, and further reports on this topic will be made when the results of experiments with ethyleneimine are published. The material in the present case was not adequately processed for other than light microscopy.

\section{References}

Barrett, A. J. (1971). The biochemistry and function of mucosubstances. Histochem. J., 3, 213-221.

Carpenter, C. P., Smyth, H. F., Jr., and Shaffer, C. B. (1948). The acute toxicity of ethylene imine to small animals. J. industr. Hyg., 30, 2-6.

Ghadially, F. N., Oryschak, A. F., and Mitchell, D. M. (1974). Nuclear fibrous lamina in pathological human synovial membrane. Virchows Arch. Abt. B, 15, 223-228.

Harwood, T. R. (1958). Diffuse perichondritis, chondritis, and iritis. Arch. Path., 65, 81-87.

Rao, K. V. S. (1954). An experimental study of regeneration in cartilage. J. Path. Bact., 67, 455-459.

Sadiq, S., Sudhakar, P. R., Sathavivalya, S., Kangwalkai, K., and Enquist, I. F. (1973). Healing in cartilage. Surg. Gynec. Obstet., 137, 953-955.

Thiess, A. M. (1965). The adverse effects of ethyleneimine exposure. Report of the Medical Department of the Badische Anilin-und Soda-Fabrik A.G., Ludwigshafenam-Rhein.

Thomas, L. (1956). Reversible collapse of rabbit ears after intravenous papain, and prevention of recovery by cortisone. J. exp. Med., 104, 245-252.

Weightman, J. and Hoyle, J. P. (1964). Accidental exposure to ethylenimine and $\mathrm{N}$-ethylethylenimine vapors. $J$. Amer. med. Ass., 189, 543-545. 